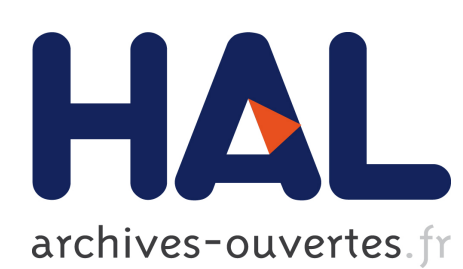

\title{
Structural and composition changes in superconducting ceramics locally irradiated by electrons
}

\author{
Yu. Ya. Tomashpol'Skii, N. V. Sadovskaya, C. Díaz-Guerra, J. Piqueras,
}

Christine Opagiste

\section{- To cite this version:}

Yu. Ya. Tomashpol'Skii, N. V. Sadovskaya, C. Díaz-Guerra, J. Piqueras, Christine Opagiste. Structural and composition changes in superconducting ceramics locally irradiated by electrons. Physics of the Solid State, American Institute of Physics, 1997, 39 (3), pp.392-396. $<10.1134 / 1.1129876>$. <hal-00566997>

\section{HAL Id: hal-00566997 \\ https://hal.archives-ouvertes.fr/hal-00566997}

Submitted on 29 Apr 2011

HAL is a multi-disciplinary open access archive for the deposit and dissemination of scientific research documents, whether they are published or not. The documents may come from teaching and research institutions in France or abroad, or from public or private research centers.
L'archive ouverte pluridisciplinaire HAL, est destinée au dépôt et à la diffusion de documents scientifiques de niveau recherche, publiés ou non, émanant des établissements d'enseignement et de recherche français ou étrangers, des laboratoires publics ou privés. 


\title{
Structural and composition changes in
}

\section{superconducting ceramics locally irradiated by electrons}

\author{
Yu. Ya. Tomashpol'ski and N. V. Sadovskaya \\ L. Ya. Karpov Physical Chemistry Scientific-Research Institute, 103064 Moscow, Russia \\ C. Diaz-Guerra and J. Piqueras \\ Universidad Complutense, Ciudad Universitaria, 28040-Madrid, Spain
}

C. Opagiste

Université de Savoie, B.P.240, 9 Rue de l'Arc-en-Ciel, F-74942 Annecy-le-Vieux, Cedex, France

\section{Abstract :}

The structural changes and the cation and anion compositions of the surface of superconducting $\mathrm{YBa}_{2} \mathrm{Cu}_{3} \mathrm{O}_{7-x}$ and $\mathrm{Tl}_{2} \mathrm{Ba}_{2} \mathrm{CuO}_{6+x}$ ceramics after local irradiation for several seconds by an electron probe with an accelerating voltage of $25 \mathrm{kV}$ and a current exceeding $10^{-7} \mathrm{~A}$ are investigated by secondary-electron emission and by cathodoluminescence and $\mathrm{x}$-ray microanalysis in a scanning electron microscope. Morphologically altered regions are detected in the irradiation epicenter, where the structure, chemical composition, and phase composition of the original compound are completely lost. In the intermediate zone between the epicenter and the periphery a distribution of the secondary emission yield is observed with a complex character that differs for the yttrium and thallium ceramics, and anomalies appear in the cathodoluminescence spectra. The experimental data are interpreted on the basis of ideas of oxygen losses under the direct influence of the electron probe and related electronic processes in superconductors.

\section{Introduction}

The influence of irradiation by fast electrons on the surface morphology, electronic structure, and chemical and phase composition is of utmost importance in superconductor research. ${ }^{1-6}$ The investigation of irradiationinduced electronic processes in a superconductor broadens our concepts of its electronic structure and real defects. The intentional alteration of the nature of the properties in individual parts of the superconducting matrix can provide a basis for local modification of the surface. The isolation of zones subjected to the influence of electron bombardment has important bearing on electron-beam lithography in potential electronics applications.

In previous studies the effect of electron irradiation of high-temperature superconductors has been investigated by transmission and scanning electron microscopy, cathodoluminescence, Raman scattering, x-ray spectral microanalysis, and Auger electron spectroscopy. The irradiation of the surface of $\mathrm{YBa}_{2} \mathrm{Cu}_{3} \mathrm{O}_{7-x}$; by electrons with energies of 150-300 keV can stimulate the formation of oxygen vacancies and disordering of the material at $\mathrm{O}(4)$ and $\mathrm{O}(5)$ sites in the $\mathrm{Cu}-\mathrm{O}$ planes. ${ }^{1}$ Structural and composition changes induced by transformation of the phase composition and by oxygen losses in electron irradiation have been detected visually with the aid of a scanning electron microscope (SEM) (Ref. 2) and by spectral methods ${ }^{3-6}$ in $\mathrm{YBa}_{2} \mathrm{Cu}_{3} \mathrm{O}_{7-x}$ and $\mathrm{Bi}_{2} \mathrm{Sr}_{2} \mathrm{CaCu}_{2} \mathrm{O}_{8+x}$. Oxygen depletion of the surface is probably one of the major phenomena encountered in the electronbeam irradiation of superconductors; the more detailed investigation of this process requires new experimental approaches suitable for local quantitative measurements otherwise unattainable by standard methods.

Based on the development of model representations of secondary electron emission processes, several secondary emission techniques have been developed in recent years with capabilities for performing phase analysis of individual grains of superconducting 
ceramics, for determining superconducting transitions in small local zones, and for measuring the oxygen content of yttriumcontaining crystals and bismuth-containing ceramics. $^{7-16}$ The model of Ref. 11 predicts an exponential dependence of the emission yield on the density of oxygen vacancies, which should make the secondary emission yield highly sensitive to the oxygen content, and model representations of the electronic subsystems in a superconducting matrix and the interaction of secondary electrons with them help to interpret the complex nature of experimental data on secondary emission from superconductors.

In this paper we demonstrate the
efficacy of using secondary-electron measurements in conjunction with cathodoluminescence, which yields information on processes in the oxygen sublattice, and also together with $x$-ray spectral microanalysis and scanning electron microscopy to study the effects of local electron irradiation of superconductors, in the example of $\mathrm{YBa}_{2} \mathrm{Cu}_{3} \mathrm{O}_{7-x}$ and $\mathrm{Tl}_{2} \mathrm{Ba}_{2} \mathrm{CuO}_{6+x}$ ceramics.

\section{Experimental}

The $\mathrm{YBa}_{2} \mathrm{Cu}_{3} \mathrm{O}_{7-x}$ ceramic was prepared by standard ceramic technology from a stoichiometric oxide mixture, which was annealed first in air and then in an oxygen atmosphere. ${ }^{17}$ Minute quantities of the phases $\mathrm{CuO}_{x}, \mathrm{BaCuO}_{2}$, and $\mathrm{Y}_{2} \mathrm{BaCuO}_{5}$ were detected together with the main phase. The superconducting transition temperature was 90 $\mathrm{K}$. The procedure used to synthesize the $\mathrm{Tl}_{2} \mathrm{Ba}_{2} \mathrm{CuO}_{6+x}$ ceramic is described in detail in Refs. 18 and 19. The starting components were $\mathrm{Tl}_{2} \mathrm{Ba}_{2} \mathrm{O}_{5}$ and $\mathrm{CuO}$ powders. Two different preparation techniques were used to obtain superconducting tetragonal or nonsuperconducting orthorhombic samples. Annealing of the samples at a low oxygen pressure showed that either type can be converted to a superconductor with an orthorhombic structure. Impurities of $\mathrm{CuO}_{x}, \mathrm{Ba}_{2} \mathrm{Cu}_{3} \mathrm{O}_{x}(<0.1 \%)$, and $\mathrm{Tl}_{2} \mathrm{Ba}_{2} \mathrm{O}_{5}(<5 \%)$ are detected, depending on the processing conditions. In our work we investigated three ceramic samples with $T c=0$, 52.4 K (orthorhombic), and 91.1 K (tetragonal).
A higher $T c$ corresponds to a lower oxygen content. We investigated the ceramic surfaces in the natural state and after polishing with diamond paste.

The secondary emission yield was measured by means of a high-vacuum $\left(10^{-7} \mathrm{~Pa}\right)$ modified BS-350 SEM with oil less pumping and a cold field-emission cathode. The output of a Thornley-Everhart secondary-electron detector was connected to a digital voltmeter, which recorded a voltage proportional to the secondary-electron current, and to a computer for processing of the signals. The measurement scheme is described in greater detail in Ref. 20. The error of determining the secondary emission yield did not exceed $1 \%$ and the energy and current of the electron probe were $16 \mathrm{keV}$ and $10^{-10}-10^{-11} \mathrm{~A}$, respectively. The primary-electron beam had scanning areas of $4.4 \times 3 \mu \mathrm{m}^{2}, 23 \times 16 \mu \mathrm{m}^{2}, 48 \times 34 \mu \mathrm{m}^{2}$, and $230 \times 160 \mu^{2}$.

The ceramic surfaces were locally irradiated with fast electrons for several seconds using a $25 \mathrm{kV}$ accelerating voltage and a probe current $>10^{-7}$ A. The irradiated areas had dimensions of $100 \times 80 \mu^{2}$ and $180 \times 50$ $\mu \mathrm{m}^{2}$.

The cathodoluminescence spectra were recorded by means of a Hitachi S-2500 electron microscope with a $25 \mathrm{kV}$ accelerating voltage at temperatures from $80 \mathrm{~K}$ to $300 \mathrm{~K}$. An optical lens was used in the measurements to focus light onto a photomultiplier mounted in the window of the sample chamber. The spectra were recorded through an optical fiber, which directed the light signal into a computerized monochromator.

The general plan of the investigations was as follows. After irradiation directly at the epicenter of the sample and along the direction from the epicenter toward the periphery, the secondary emission yield was measured, and the cathodoluminescence spectra were recorded. Elemental analysis of the composition and morphology observations were performed at the same locations by means of a JEM-35 CF SEM with a LINK attachment or a JSM-6400 SEM. The secondary emission in the intermediate zone was measured in $16 \mu \mathrm{m}$ to $100 \mu \mathrm{m}$ steps; a $1 \mu \mathrm{m}$ step was used for the elemental composition measurements. 


\section{Results and discussion}

After the surface had been irradiated, we distinguished its epicenter as determined by the scanning area of the electron-beam probe, an intermediate zone in which changes took place under the influence of the epicenter, and the periphery, i.e., the remaining zone unaffected by irradiation.

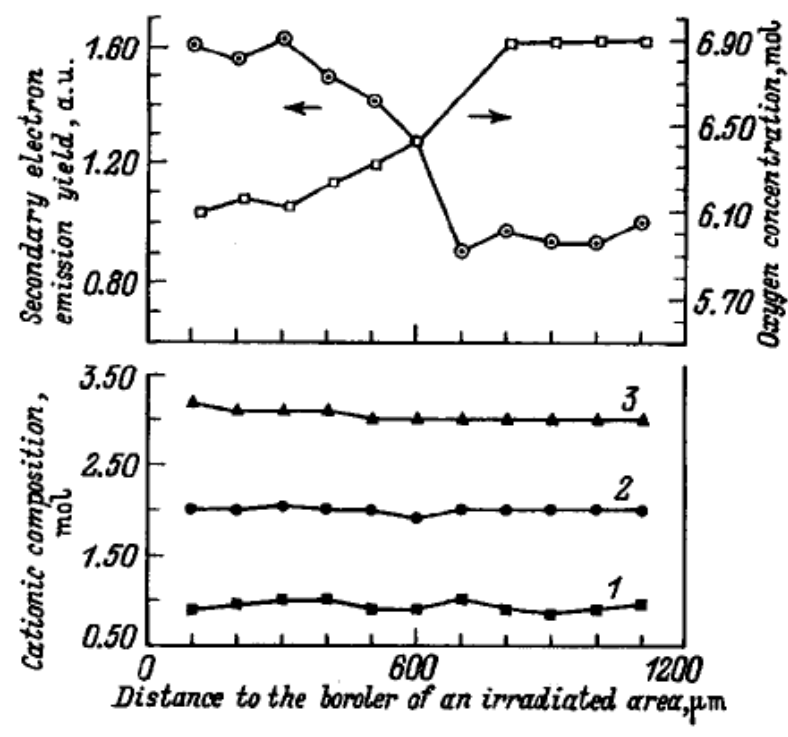

FIG. 1. Secondary-electron emission yield, cation composition, and oxygen content vs distance from the irradiation epicenter to the periphery for $\mathrm{YBa}_{2} \mathrm{Cu}_{3} \mathrm{O}_{7-x}$ ceramic $(T c=90 \mathrm{~K})$. Cation composition distribution curves: 1) $\mathrm{Y}$; 2) $\mathrm{Ba}$; 3$) \mathrm{Cu}$.

The morphology of the surface was completely altered at the irradiation epicenter in both the yttrium-containing and the thalliumcontaining ceramics. The coarser relief and other morphological features indicate that irradiation is accompanied by melting with subsequent hardening and elements of recrystallization. The secondary emission yield measured over a large area in both ceramics is always higher than in the intermediate and peripheral zones. More localized measurements taking topographical irregularities into account indicate a higher emission yield in isolated parts of the epicenter. Here the cation elemental composition is always non uniform and in most cases differs from the almost stoichiometric composition in the periphery. In the case of the yttrium ceramic, for example, a $\mathrm{Y}_{2} \mathrm{O}_{3}$ phase and copper depleted phases are detected in the epicenter; for the thallium ceramic significant thallium losses and barium enrichment are observed. In this light it is natural to associate the increase in the secondary emission yield with changes in the type of electronic structure in the epicenter toward semiconducting or insulator phases according to data in Refs. 8 and 10. The phase transformations associated with modification of the cation composition appear to be corroborated by the cathodoluminescence spectra. It is conceivable that the superposition of $\mathrm{Y}_{2} \mathrm{O}_{3}$ and $\mathrm{Y}_{a} \mathrm{Ba}_{b} \mathrm{O}_{x}$ phases is responsible for modifying the cathodoluminescence spectrum from the epicenter in the yttrium ceramic (in contrast with the periphery), and the appearance of the $590 \mathrm{~nm}$ band in the cathodoluminescence spectrum reflects the changes in the cation composition in the epicenter of the $\mathrm{Tl}_{2} \mathrm{Ba}_{2} \mathrm{CuO}_{6+x}$ ceramic. The contents of these phases increase as the irradiation time is prolonged.

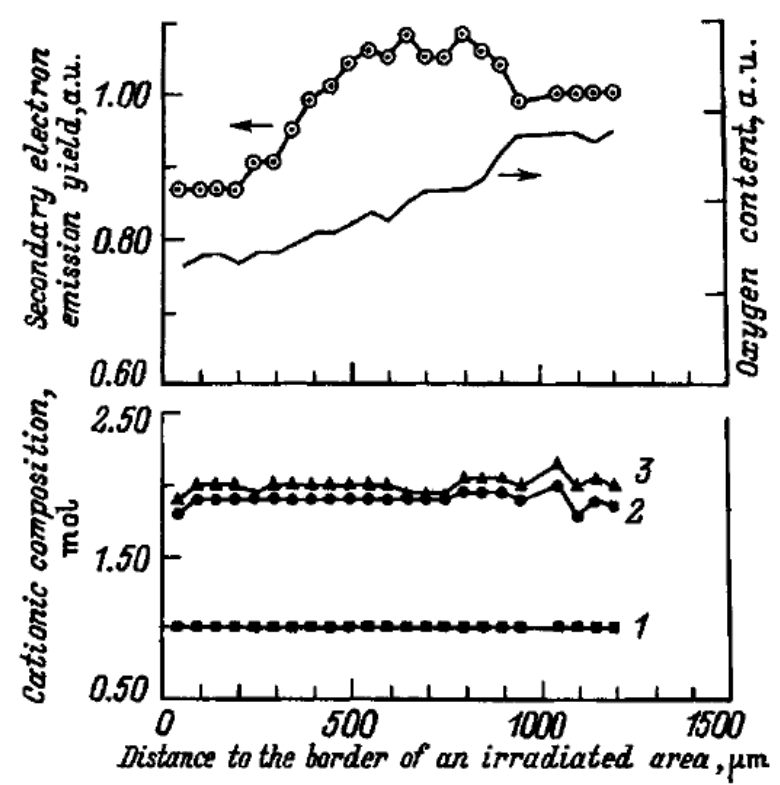

FIG. 2. The same as Fig. 1, for $\mathrm{Tl}_{2} \mathrm{Ba}_{2} \mathrm{CuO}_{6+x}$ ceramic without final annealing $(T c=0 K)$. Cation composition distribution curves: 1) $\mathrm{Cu}$; 2) $\mathrm{Ba}_{2}$; 3) Tl.

The changes in the intermediate zone are of considerable interest. Figure 1 shows the distribution of the secondary emission yield and the cation composition along the direction from the epicenter to the periphery in the $\mathrm{YBa}_{2} \mathrm{Cu}_{3} \mathrm{O}_{7-x}$ ceramic; the results of analogous measurements for the $\mathrm{Tl}_{2} \mathrm{Ba}_{2} \mathrm{CuO}_{6+x}$ ceramic are shown in Fig. 2. Since the metals composition remains stable in the periphery and in the intermediate zone up to the edge of the irradiated zone, and since the surface morphology is left unaltered, we identify the 
shape of the secondary emission distribution with non uniform oxygen losses. The boundary between the intermediate zone and the periphery, where the oxygen content is stabilized, is determined by the point on the yield curve separating its variable and constant parts. It is evident from the figures that the linear dimensions of the intermediate zone are much greater than those of the epicenter, exceeding $1000 \mu \mathrm{m}$. Of all the causes leading to surface oxygen losses, the most likely is the brief temperature rise due to radiation heating of the epicenter with a temperature gradient toward the periphery. Rapid cool down prevents the losses of oxygen from being compensated by its diffusion from the interior depth. Effects of this nature, which lead to the thermally stimulated surface segregation of oxygen, have been observed in $\mathrm{BaTiO}_{3}$ and $\mathrm{SrTiO}_{3}$ (Ref. 21).

The oxygen losses in the intermediate zone are confirmed by cathodoluminescence data (Fig. 3). The $540 \mathrm{~nm}$ band, whose formation also involves a contribution from oxygen vacancies, ${ }^{3,22}$ is very pronounced in the spectrum of the intermediate zone and is weaker in the spectrum of the peripheral zone. A reduction in oxygen content near the irradiated zone has also been observed by Raman scattering. ${ }^{3}$

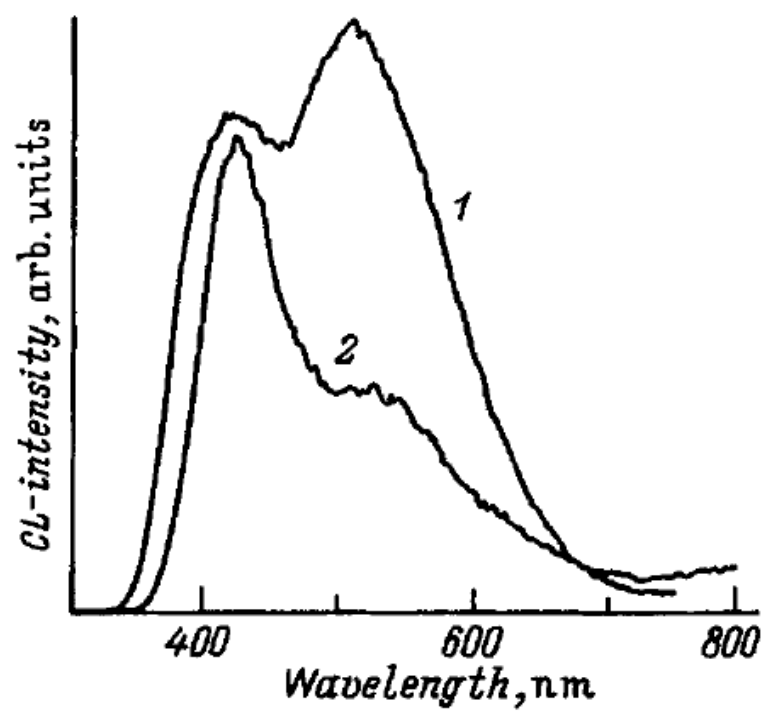

FIG. 3. Cathodoluminescence spectra from for $\mathrm{Tl}_{2} \mathrm{Ba}_{2} \mathrm{CuO}_{6+x}$ ceramic, recorded at $80 \mathrm{~K}$ from different zones: 1) intermediate zone; 2) periphery.

The difference in the nature of the distribution of the secondary emission yield for the yttrium and thallium ceramics is attributable to specific characteristics of their electronic structures. Figure 4 shows the dependence of the secondary emission yield on the oxygen content in $\mathrm{YBa}_{2} \mathrm{Cu}_{3} \mathrm{O}_{7-x}, \mathrm{Tl}_{2} \mathrm{Ba}_{2} \mathrm{CuO}_{6+x}$ and for comparison in $\mathrm{Bi}_{2} \mathrm{Sr}_{2} \mathrm{CaCu}_{2} \mathrm{O}_{8+x}$. As mentioned in Ref. 23, in the orthorhombic phase of $\mathrm{YBa}_{2} \mathrm{Cu}_{3} \mathrm{O}_{7-x}$ the decrease in the hole density and the increase in the electron density with increasing value of $x$ almost cancel each other, so that the secondary emission yield in the superconducting region changes insignificantly.
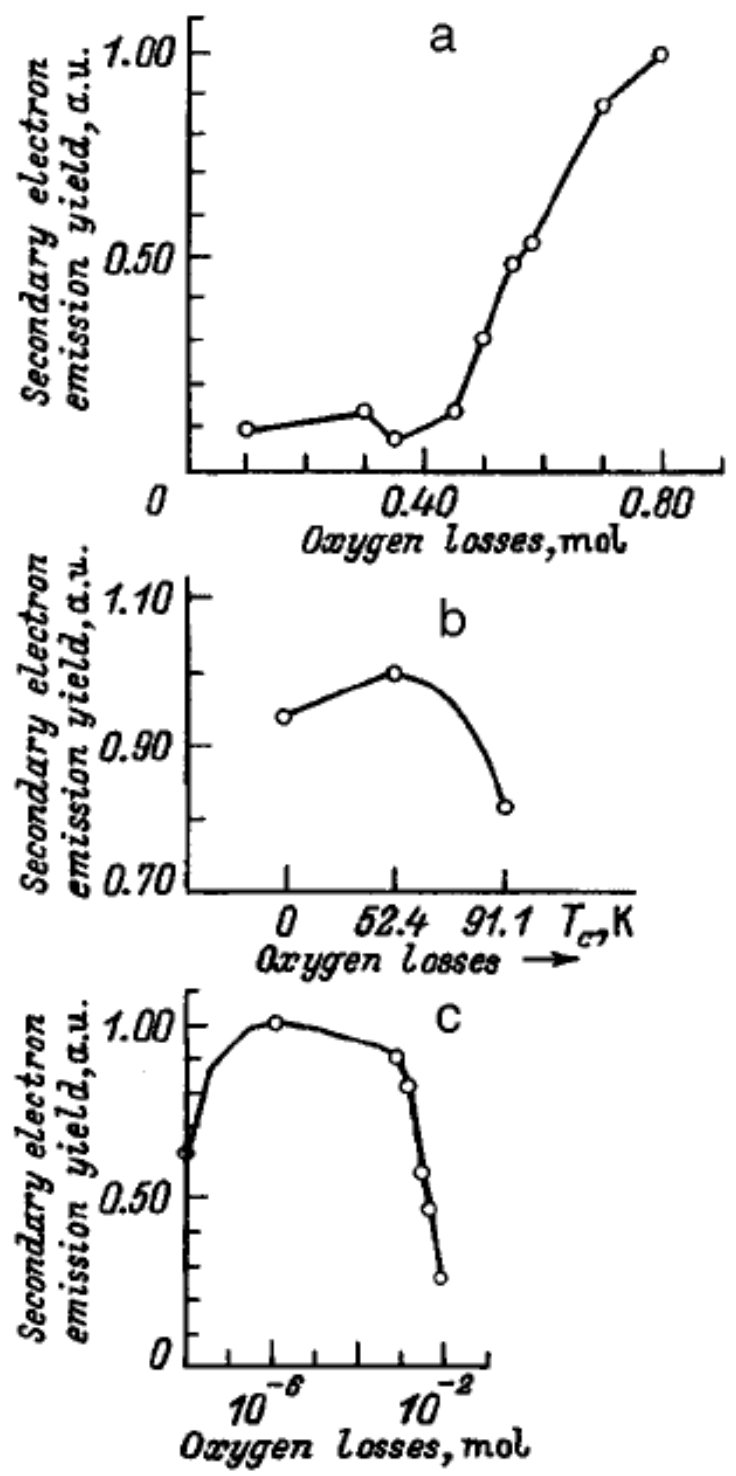

FIG. 4. Secondary emission yield vs oxygen losses for various ceramics. a) $\mathrm{YBa}_{2} \mathrm{Cu}_{3} \mathrm{O}_{7-x}$; b) $\mathrm{Tl}_{2} \mathrm{Ba}_{2} \mathrm{CuO}_{6+x}$; c) $\mathrm{Bi}_{2} \mathrm{Sr}_{2} \mathrm{CaCu}_{2} \mathrm{O}_{8+x}$. For the yttrium ceramic the oxygen deficit is calculated from $\mathrm{x}$-ray structural data, ${ }^{9}$ and for the thallium ceramic the oxygen losses are estimated qualitatively from data $^{24}$ relating the transition temperature to the oxygen content; the oxygen loss data for the bismuth ceramic are taken from Ref. 23 .

In the tetragonal phase, as $x$ is increased, the hole-type conductivity not only leads to the compensation of donor-level electrons, but also 
causes the density of holes to decrease in advance, so that the secondary emission yield rises considerably as the oxygen losses increase.

The nature of the dependence of the secondary emission yield on the oxygen losses is altogether different in $\mathrm{Tl}_{2} \mathrm{Ba}_{2} \mathrm{CuO}_{6+x}$ and $\mathrm{Bi}_{2} \mathrm{Sr}_{2} \mathrm{CaCu}_{2} \mathrm{O}_{8+x}$. To explain the form of this function in Bi-containing superconductors, we consider a model incorporating two electronic subsystems (I and II), which contain (respectively) electrons generated by oxygen vacancies and weakly bound electrons equivalent to the number of holes. ${ }^{23}$ This model is consistent with existing notions concerning electronic processes in high-Tc superconductors with "'excess"' oxygen, ${ }^{24-26}$ where not only the existence of the electronic subsystems is postulated, but also those subsystems are localized in different parts of the crystal structure (e.g., holes in $\mathrm{Cu}-\mathrm{O}$ planes, electrons at $\mathrm{O}(4)$ sites, etc.). It is also possible for the subsystems to interact when changes take place in the density of vacancies. ${ }^{26}$

To account for the onset of the maximum of the curve of the secondary emission yield versus the oxygen content, we consider the basic expression for the secondaryelectron emission yield ${ }^{11}$ :

$$
\Delta=\beta n \lambda[\exp (-\lambda / L)] B,
$$

where the factor $\beta n \lambda$ describes the generation of a secondary electron ( $\beta$ is the secondaryelectron cross section of interaction with the primary electron, $n$ is the carrier density, and $\lambda$ is the escape depth of the secondary electron, the factor $\exp (-\lambda / L)$ refers to scattering of the secondary electron by electrons and phonons ( $L$ is the mean free path of the secondary electron), and $B$ is the probability of the secondary electron overcoming the surface barrier. If we regard $x$ as a parameter, it suffices to keep only the dominant exponential factor. The influence of this factor is essentially to differentiate between interaction of the secondary electron with electrons generated by oxygen vacancies $\left(L_{e}=1 / \alpha_{e} n_{e}\right)$ and with weakly bound electrons equivalent to the number of holes $\left(L_{h}=1 /\right.$ $\alpha_{h} n_{h}$ ), where $\alpha_{e}$ and $\alpha_{h}$ are the cross sections of interaction of the secondary electron with electrons of subsystems I and II, respectively. Analyzing the exponential factor $\exp \left(-\lambda\left(\alpha_{e} n_{e^{+}} \alpha_{h} n_{h}\right)\right)$, as a function of the oxygen "excess" $x$, we see that as $x$ is decreased (along with the oxygen content), the density of vacancy-generated electrons increases, while the density of holes (and of weakly bound electrons) decreases. The final result depends on the mechanism of interaction of subsystems I and II, the initial hole density $n_{h}$, the difference between $\alpha_{e}$ and $\alpha_{h}$, and the maximum possible oxygen losses. In $\mathrm{Bi}_{2} \mathrm{Sr}_{2} \mathrm{CaCu}_{2} \mathrm{O}_{8+x}$, for example, the hole density drops appreciably for very small oxygen losses (hundredths to thousandths of a mole), ${ }^{27}$ and the emission yield increases. With a further decrease in $x$ the density of "vacancion" electrons increases, and the secondary emission yield decreases. As a result, the curve representing the dependence of the yield on the oxygen losses acquires a maximum.

We are therefore looking at a qualitative analogy between $\mathrm{Tl}-$ and Bi-containing ceramics, ${ }^{23}$ in which the secondary emission yield varies non monotonically with the oxygen content. Against the qualitative similarity of the mechanism underlying the interaction of the electronic subsystems we find quantitative differences associated, in particular, with the different initial hole densities.

In any case the secondary emission yield in either ceramic with $x>0$ is higher than for $x$ $\approx 0$. When the oxygen content falls below the limiting value, the secondary emission yield depends on the emission properties of the new phases created by the disintegration of the matrix.

In discussing the analytical aspect, it is important to emphasize that secondary-electron emission spectroscopy is highly sensitive to small changes in the oxygen concentration (as little as $10^{-5} \mathrm{~mol}$; Ref. 23), and this consideration includes samples of superconductors with a surface oxygen concentration gradient.

Using a calibration curve previously obtained for $\mathrm{YBa}_{2} \mathrm{Cu}_{3} \mathrm{O}_{7-x}$ (Ref. 14), we have calculated the oxygen distribution in the intermediate zone (Fig. 1), from which it follows that semiconducting zones are formed as a result of oxygen losses in the superconducting matrix. Lacking an accurate calibration curve for the $\mathrm{Tl}_{2} \mathrm{Ba}_{2} \mathrm{CuO}_{6+x}$ ceramic, we have plotted a qualitative oxygen 
distribution curve on the surface (Fig. 2). These distributions nonetheless reveal a monotonic decrease in the oxygen concentration from the periphery toward the epicenter, and in fact this process creates a variation of the superconducting transition temperatures in the intermediate zone.

\section{Conclusion}

To summarize, we have used secondaryelectron emission measurements in conjunction with cathodoluminescence and x-ray spectral microanalysis to show that local electron irradiation produces zones around the epicenter with dimensions in the hundreds of micrometers, wherein oxygen losses are induced by a temperature gradient associated with brief transient heating and rapid cooldown. Quantitative measurements of the oxygen distribution have shown that regions with variable transition temperatures $T c$ and with semiconducting properties can form on the surface of a superconductor. The distribution of the secondary-electron emission yield in the intermediate zones is similar for $\mathrm{Ti}$ and $\mathrm{Bi}$ containing ceramics and differs for a Ycontaining ceramic. The cause is rooted in the parameters of the electronic subsystems and their interaction as the oxygen content varies. Secondary-electron emission characterization of the zones formed by electron irradiation can provide a means for the preparation of standard samples suitable for comparison in quantitative measurements of oxygen content in oxid compounds. At the same time, there is an obvious need for spatial thermal effects to be taken into account in the electron-probe analysis of superconductors.

\section{Acknowledgements}

The authors are grateful to S. G. Prutchenko for assistance with the elemental analysis.

This work has been carried out under the auspices of RNTK AP SFSK (subprogram "High Temperature Superconductivity," Project 93079) and has received support from the Russian Fund for Fundamental Research
(Project 96-03- 32068a), Grant HTECH.LG941034, DGIGYT Project PB 931256, and CICYT Project MAT 95-1184E.

\section{References:}

${ }^{1}$ S. N. Basu, T. E. Mitchell, and M. Nastasi, J. Appl. Phys. 69, 3167 (1991).

2 L. S. Kokhanchik and A. V. Chernykh, Izv. Akad. Nauk Ser. Fiz. 57, 9 (1992).

${ }^{3}$ P. Gomez, J. Jimenez, P. Martin, J. Piqueras, and F. Dominquez-Adame, J. Appl. Phys. 74, 6289 (1993).

${ }^{4}$ P. Gomez, J. Piqueras, M. J. Sayagues, and J. M. Gonzalez-Calbet, Solid State Commun. 96, 45 (1995).

5 A. Torres, J. Jimenez, P. Gomes, and J. Piqueras, Mater. Res. Soc. Symp. Proc. 373, 431 (1995).

${ }^{6}$ S. Matsui, T. Ichinoshi, T. Yoshitake, S. Miura, T. Satoh, and M. Mito, J. Vac. Sci. Technol. B 8, 1771 (1990).

${ }^{7}$ Yu. Ya. Tomashpolsky, M. A. Sevostianov, N. V. Sadovskaya, and N. V. Kolganova, J. Microsc. Spectrosc. Electron. 14, 213 (1989).

${ }^{8}$ Yu. Ya. Tomashpol'skié, M. A. Sevost'yanov, N. V. Kolganova, N. V. Sadovskaya, S. V. Kostromina, and O. V. Fedoseeva, Sverkhprovodimost' (KIAE) 2(6), 15 (1989) (Superconductivity 2(6), 17 (1989)).

${ }^{9}$ Yu. Ya. Tomashpol'skié, N. V. Sadovskaya, E. D. Politova, and N. V. Kolganova, Sverkhprovodimost' (KIAE) 5, 457 (1992) (Superconductivity 5, 451 (1992)).

${ }_{10}$ Yu. Ya. Tomashpol'skié, M. A. Sevost'yanov, N. V. Sadovskaya, N. V. Kolganova, and N. G. Shirina, Fiz. Tverd. Tela (Leningrad) 31(11), 26 (1989) (Sov. Phys. Solid State 31, 1852 (1989)).

11 Yu. Ya. Tomashpolsky, Ferroelectrics 144, 231 (1993).

12 Yu. Ya. Tomashpol'skié and N. V. Sadovskaya, Fiz. Tverd. Tela (St. Petersburg) 37, 1108 (1995) (Phys. Solid State 37, 603 (1995)).

${ }^{13}$ Yu. Ya. Tomashpolsky, Ferroelectrics 163, 115 (1995).

14 Yu. Ya. Tomashpolsky and N. V. Sadovskaya, Ferroelectrics 163, 129 (1995).

15 Yu. Ya. Tomashpolsky and N. V. Sadovskaya, Ferroelectrics 170, 97 (1995).

${ }^{16}$ Yu. Ya. Tomashpol'skié, N. V. Sadovskaya, 
and E. V. Mamontov, Izv. Ross. Akad. Nauk Ser. Fiz. 60, 138 (1996).

${ }^{17}$ U. V. Mamontov, N. V. Sadovskaya, and Yu. Ya. Tomashpol'skié, Sverkhprovodimost' (KIAE) 8, 186 (1995) (Superconductivity 8 (1988)).

${ }^{18}$ C. Opagiste, M. Couach, A. F. Cohen-Adad, A. Junod, C. Triscone, and J. Müller, J. Alloys Compounds 196, 47 (1993).

${ }^{19}$ C. Opagiste, G. Triscone, M. Couach, T. K. Jondo, J. L. Jorda, A. Junod, A. F. Khoder, and J. Müller, Physica C 213, 17 (1993).

${ }^{20}$ Yu. Ya. Tomashpol'skié, Zavod. Lab. 58, 30 (1992).

${ }^{21}$ Yu. Ya. Tomashpolsky, I. Ya. Kolotyrkin, and E. N. Lubnin, J. Microsc. Spectrosc. Electron. 10, 521 (1985).
${ }^{22}$ C. Diaz-Guerra, J. Piqueras, and C. Opagiste, Physica C 259, 121 (1996).

${ }^{23}$ Yu. Ya. Tomashpol'skié, N. V. Sadovskaya, E. D. Politova, I. A. Ol'khovik, and N. G. Shirina, Sverkhprovodimost' (KIAE) 6, 1479 (1993).

${ }^{24}$ Y. Shimakawa, Y. Kubo, T. Manako, and H. Igarashi, Phys. Rev. B 40, 11400 (1989).

${ }^{25}$ C. Martin, A. Maignan, J. Provost, C. Michel, M. Hervieu, R. Tournier, and B. Raveau, Physica C 168, 8 (1990).

${ }^{26}$ Y. Shimakawa, Y. Kubo, T. Manako, and H. Igarashi, Phys. Rev. B 42, 10165 (1990).

${ }^{27}$ M. Nagoshi and T. Suzuki, Phys. Rev. B 43, 10445 (1991). 